\title{
Creatine and guanidinoacetate transport at blood-brain and blood-cerebrospinal fluid barriers
}

\author{
Olivier Braissant
}

Received: 13 September 2011 /Revised: 22 November 2011 / Accepted: 30 November 2011 / Published online: 18 January 2012

(C) SSIEM and Springer 2012

\begin{abstract}
While it was thought that most of cerebral creatine is of peripheral origin, AGAT and GAMT are well expressed in CNS where brain cells synthesize creatine. While the creatine transporter SLC6A8 is expressed by microcapillary endothelial cells (MCEC) at blood-brain barrier (BBB), it is absent from their surrounding astrocytes. This raised the concept that BBB has a limited permeability for peripheral creatine, and that the brain supplies a part of its creatine by endogenous synthesis. This review brings together the latest data on creatine and guanidinoacetate transport through BBB and blood-CSF barrier (BCSFB) with the clinical evidence of AGAT-, GAMT- and SLC6A8deficient patients, in order to delineate a clearer view on the roles of BBB and BCSFB in the transport of creatine and guanidinoacetate between periphery and CNS, and on brain synthesis and transport of creatine. It shows that in physiological conditions, creatine is taken up by CNS from periphery through SLC6A8 at BBB, but in limited amounts, and that CNS also needs its own creatine synthesis. No uptake of guanidinoacetate from periphery occurs at BBB except under GAMT deficiency, but a net exit of guanidinoacetate seems to occur from CSF to blood at BCSFB, predominantly through the taurine transporter TauT.
\end{abstract}

Communicated by: Cornelis Jakobs

Competing interest: None declared.

Presented at the Annual Symposium of the SSIEM, Geneva, Switzerland, August 30 - September 2, 2011.

O. Braissant $(\bowtie)$

Inborn Errors of Metabolism, Service of Biomedicine,

Lausanne University Hospital,

Avenue Pierre-Decker 2, CI 02/33,

CH-1011 Lausanne, Switzerland

e-mail: Olivier.Braissant@chuv.ch

\section{Introduction}

In the brain as in most tissues, the creatine $(\mathrm{Cr}) /$ phosphocreatine ( $\mathrm{PCr}) /$ creatine kinase $(\mathrm{CK})$ system plays essential roles to maintain the high energy levels necessary for CNS development and functions, through regeneration and buffering of ATP levels (Brosnan and Brosnan 2007; Wyss and Kaddurah-Daouk 2000). Recent works suggest that $\mathrm{Cr}$ in CNS may also act as true neurotransmitter and one of the main CNS osmolytes (Almeida et al. 2006; Bothwell et al. 2002). In mammals, half of $\mathrm{Cr}$ is obtained from diet, the other half being synthesized endogenously by a two-step mechanism involving arginine:glycine amidinotransferase (AGAT; EC 2.1.4.1; gene: GATM) and guanidinoacetate methyltransferase (GAMT; EC 2.1.1.2; gene: GAMT). $\mathrm{Cr}$ is distributed by blood to tissues and taken up by cells through a specific Cr transporter, SLC6A8 (gene: SLC6A8), also called CT1, CRT1, CRTR, CTR or CreaT (Wyss and Kaddurah-Daouk 2000).

The brain is protected from variations in the blood milieu by different barriers which tightly regulate exchanges between periphery and CNS, the two most important being blood-brain barrier (BBB) and blood-cerebrospinal fluid barrier (BCSFB). BBB represents, by many orders of magnitude, the largest barrier between periphery and the brain (Fig. 1). It consists of non-fenestrated microcapillary endothelial cells (MCEC) connected together by tight and adherent junctions that prevent paracellular diffusion of molecules between blood and CNS parenchyma (Engelhardt and Sorokin 2009). Specifically expressed transporters on luminal and abluminal sides of MCEC, together with a very limited pinocytosis, allow the tight regulation of exchanges through BBB. Moreover, these exchanges are also strongly regulated by (i) cells adjacent to the abluminal side of MCEC (namely pericytes which cover about $32 \%$ of the microcapillary surface; 

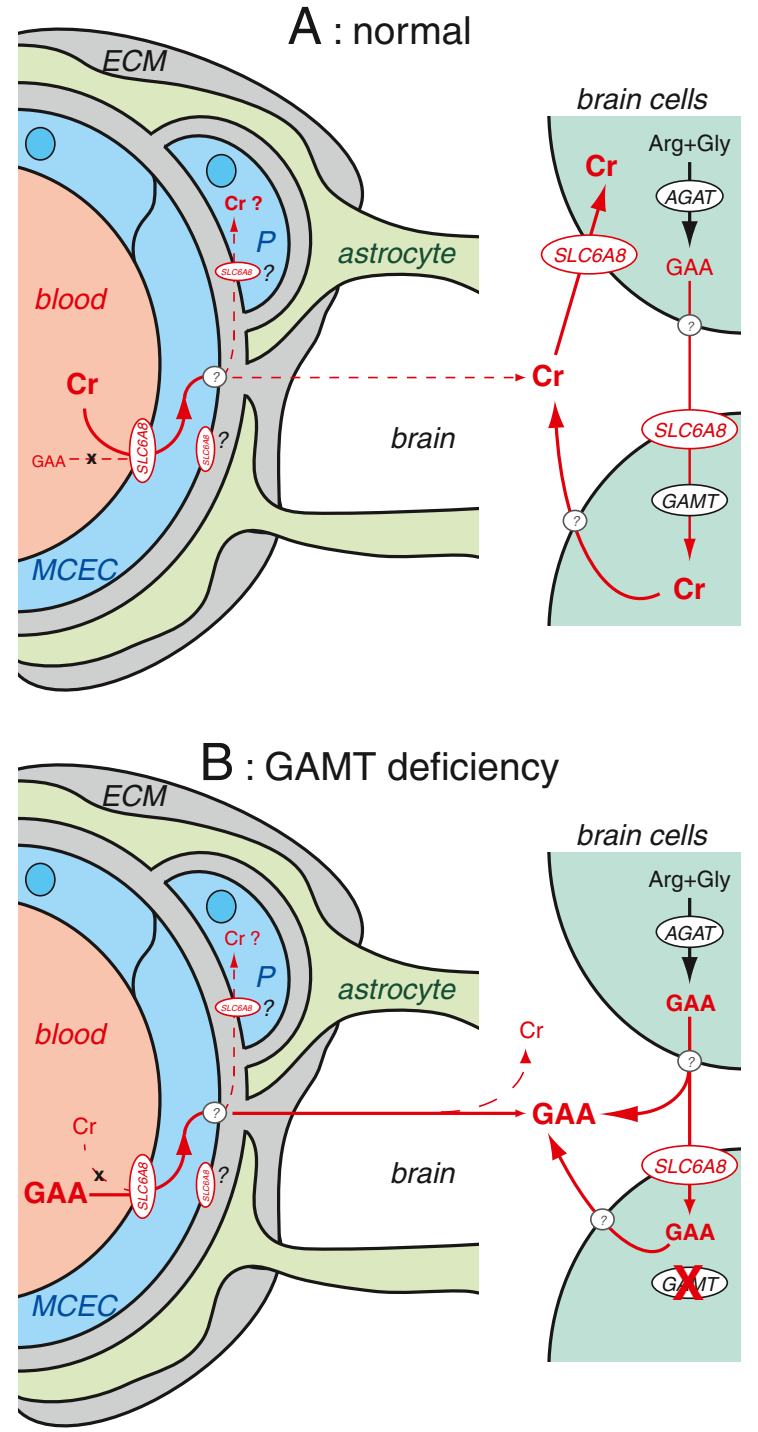

Fig. 1 Transport of creatine (Cr) and guanidinoacetate (GAA) at the blood-brain barrier (BBB). a: in normal conditions; b: under GAMT deficiency. In normal conditions (a), $\mathrm{Cr}$ is taken up by $\mathrm{CNS}$ from periphery through SLC6A8 expressed on MCEC at BBB, but in limited amounts in reason of the absence of SLC6A8 in the surrounding astrocytes and the difficult diffusion of $\mathrm{Cr}$ through ECM surrounding BBB. Therefore, the brain needs its own synthetic pathway to ensure sufficient levels of $\mathrm{Cr}$, and do so by expressing AGAT and GAMT. No uptake of GAA from periphery occurs at BBB, except under GAMT deficiency (b) and maybe also SLC6A8 deficiency. Arg: arginine; AGAT: arginine:glycine amidinotransferase; $\mathrm{Cr}$ : creatine; ECM: extracellular matrix; GAA: guanidinoacetate; GAMT: guanidinoacetate methyltransferase; Gly: glycine; MCEC: microcapillary endothelial cells (BBB); P: pericyte; SLC6A8: Cr transporter

and astrocytic feet which cover more than $98 \%$ of the surface made by MCEC and pericytes; Cardoso et al. 2010; Neuwelt et al. 2011) and (ii) a specific extracellular matrix which sheathes MCEC, pericytes and astrocytic feet and limits the diffusion of molecules between MCEC and CNS (Dityatev et al. 2010). BCSFB (Fig. 2), located in lateral, third and fourth
A : normal
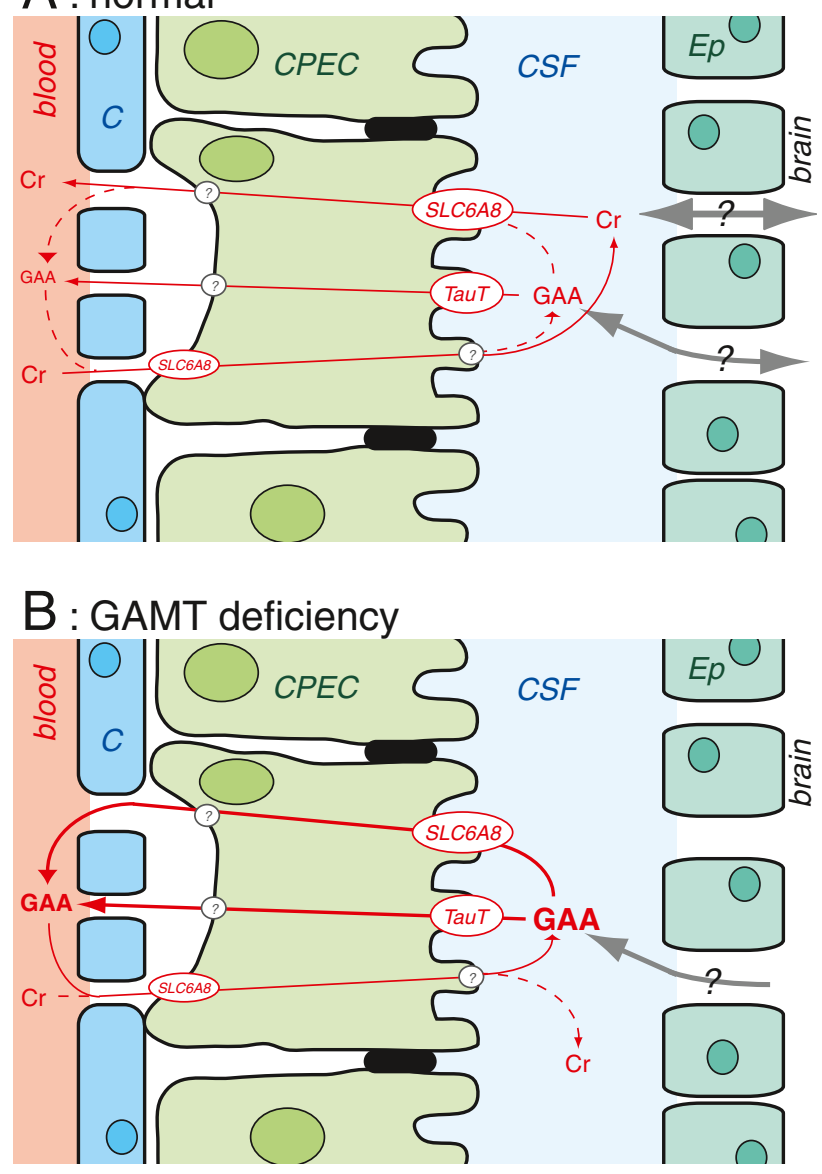

Fig. 2 Transport of creatine $(\mathrm{Cr})$ and guanidinoacetate $(\mathrm{GAA})$ at the blood-cerebrospinal fluid barrier (BCSFB). a: in normal conditions; $\mathbf{b}$ : under GAMT deficiency. In normal conditions (a), CPEC are able to take up Cr both from blood and CSF; a net exit of GAA seems to occur from CSF to blood at BCSFB under physiological conditions, predominantly through TauT. This exit of GAA from CSF to blood may be increased under GAMT deficiency (b), and uses both TauT and SLC6A8. CPEC: choroid plexus epithelial cells (BCSFB); Cr: creatine; CSF: cerebrospinal fluid; Ep: ependymal epithelium; GAA: guanidinoacetate; SLC6A8: Cr transporter; TauT: taurine transporter

ventricles, is made by unique apical tight junctions between the choroid plexus epithelial cells (CPEC), which are responsible of the secretion of CSF and also express specific transporters allowing regulated exchanges between CSF and blood (Engelhardt and Sorokin 2009; Spector 2010; Wolburg and Paulus 2010).

While it was thought that most, if not all, cerebral Cr is of peripheral origin, AGAT and GAMT are well expressed in CNS where brain cells can synthesize their own $\mathrm{Cr}$ (Béard and Braissant 2010; Braissant et al. 2008). In brain parenchyma, SLC6A8 is expressed by neurons and oligodendrocytes. However, while SLC6A8 is also expressed by MCEC at $\mathrm{BBB}$, allowing CNS to import $\mathrm{Cr}$ from periphery, it is absent from astrocytes, particularly from their feet lining 
BBB (Braissant et al. 2001b; Ohtsuki et al. 2002; Tachikawa et al. 2004). This raised the concept that BBB has a limited permeability for peripheral $\mathrm{Cr}$, and that the brain supplies a part of its $\mathrm{Cr}$ by endogenous synthesis (Braissant et al. 2001b; Braissant et al. 2011; Braissant and Henry 2008). However, despite indeed a limited efficiency of brain $\mathrm{Cr}$ uptake from periphery, shown in vivo both in rodents (Ohtsuki et al. 2002; Perasso et al. 2003) as well as in AGAT- and GAMT-deficient patients (AGAT: OMIM \#612718; GAMT: OMIM \#612736) treated by Cr (Schulze 2005), Cr (and the intermediate guanidinoacetate, GAA) do cross BBB and BCSFB (Tachikawa and Hosoya 2011).

This review brings together (i) the latest experimental data on the transport of $\mathrm{Cr}$ and GAA through BBB and BCSFB with (ii) the clinical evidence shown in the patients deficient for AGAT, GAMT and SLC6A8 (SLC6A8: OMIM $\# 300352$ ), in order to delineate a clearer view of the roles of $\mathrm{BBB}$ and $\mathrm{BCSFB}$ in the transport of $\mathrm{Cr}$ and GAA between periphery and $\mathrm{CNS}$, and on the synthesis and transport of $\mathrm{Cr}$ within the brain, both in the mature brain and during development.

\section{$\mathrm{Cr}$ and GAA through BBB and BCSFB, and within CNS}

It is thought that most of peripheral synthesis of $\mathrm{Cr}$ occurs through AGAT in kidney and GAMT in liver (Brosnan and Brosnan 2007), implying the transport of the intermediate GAA through blood circulation. $\mathrm{Cr}$ is also synthesized in the mammalian brain (Béard and Braissant 2010; Pisano et al. 1963). The recent knowledge of how AGAT and GAMT, as well as the $\mathrm{Cr}$ transporter SLC6A8, are expressed and active at $\mathrm{BBB}$ and $\mathrm{BCSFB}$, as well as within CNS, sheds light on the respective importance of $\mathrm{Cr}$ synthesis within the brain versus $\mathrm{Cr}$ and GAA uptake from periphery or release from CNS.

AGAT and GAMT are well expressed in the brain, where they are found, in all CNS structures, in every main cell types (neurons, astrocytes and oligodendrocytes; Braissant et al. 2001b; Nakashima et al. 2005; Schmidt et al. 2004; Tachikawa et al. 2004). We have shown recently that AGAT and GAMT, in most regions of the rat brain, appear expressed in a dissociated way, being rarely co-expressed within the same cell (Braissant et al. 2010). AGAT, but not GAMT, is expressed by MCEC at BBB (Braissant et al. 2001b; Tachikawa et al. 2004), while AGAT and GAMT are expressed by choroid plexus at BCSFB (Braissant et al. 2001b).

SLC6A8 is also expressed throughout the mammalian brain in neurons and oligodendrocytes (Braissant et al. 2001b; Happe and Murrin 1995; Mak et al. 2009; Schloss et al. 1994; Tachikawa et al. 2008). However, in physiological conditions and in contrast to AGAT and GAMT, it cannot be detected in astrocytes (Acosta et al. 2005; Braissant et al. 2001b; Nakashima et al. 2004), except for very few in cerebellum (Mak et al. 2009). In contrast to its absence from the astrocytic feet lining microcapillaries, SLC6A8 is present in MCEC making BBB, where it is expressed at both luminal and abluminal sides of MCEC (Braissant et al. 2001b; Ohtsuki et al. 2002; Tachikawa et al. 2004) (Fig. 1). At BCSFB, SLC6A8 is mainly expressed at the brush-border membrane of choroid plexus epithelial cells, and to a lesser extent on their basal membrane (Braissant et al. 2001b; Tachikawa et al. 2008) (Fig. 2).

Peripheral $\mathrm{Cr}$ can enter the brain. In vivo experiments in mouse and rat have demonstrated that CNS can take up $\mathrm{Cr}$ from the blood against its concentration gradient, at least to some extent (Ohtsuki et al. 2002; Perasso et al. 2003). However, it has been known for a very long time that this passage of peripheral $\mathrm{Cr}$ into the brain is limited. Oral treatment of normal rats with $\mathrm{Cr}$ does not increase their CNS Cr content (Chanutin 1927), while oral administration of $\mathrm{Cr}$ in healthy human volunteers with about 60 times the daily needs in $\mathrm{Cr}$ only leads to a very modest $5 \%$ to $10 \%$ increase in their brain total $\mathrm{Cr}(\mathrm{Cr}+\mathrm{PCr})$ after one month of treatment (Dechent et al. 1999). The restricted crossing of peripheral $\mathrm{Cr}$ into $\mathrm{CNS}$ is also illustrated in $\mathrm{Cr}$ orally-treated AGAT- and GAMT-deficient patients who, despite the high doses of Cr used (usually 0.35-2.00 g/kg/day; 20-120 times the normal needs in $\mathrm{Cr}$ ), replenish their cerebral $\mathrm{Cr}$ only slowly, $\mathrm{Cr}$ restoration taking months and remaining in most cases only partial (Battini et al. 2002; Ganesan et al. 1997; Item et al. 2001; Schulze 2005; Schulze et al. 1998; Stöckler et al. 1996). $\mathrm{GAMT}^{-/} \mathrm{KO}$ mice treated with the high dose of $2 \mathrm{~g} / \mathrm{kg}$ /day of $\mathrm{Cr}$ normalize their brain $\mathrm{Cr}$ after 16 to 35 days of treatment, depending on CNS region (Kan et al. 2007).

At BBB (Fig. 1), in vivo analysis in mouse has shown that the carrier-mediated uptake of $\mathrm{Cr}$ from blood to brain through $\mathrm{BBB}$ has an influx transport clearance of $1.6 \mu \mathrm{L} /$ (min*g brain) (Ohtsuki et al. 2002), about six times greater than that of sucrose, for which BBB is not permeable, but about 50 times smaller than that of glucose (Hasselbalch et al. 1995). Using TM-BBB4 cells (conditionnally immortalized mouse brain capillary endothelial cells) as in vitro model for BBB, Ohtsuki et al. showed that $\mathrm{Cr}$ is taken up by TM-BBB 4 cells by a $\mathrm{Na}^{+} / \mathrm{Cl}^{-}$-dependent carrier having a $\mathrm{Km}$ of $16 \mu \mathrm{M}$ and being strongly inhibited by guanidinopropionate and GAA, presenting thus characteristics of SLC6A8 which is expressed at BBB in MCEC (Braissant et al. 2001b; Ohtsuki et al. 2002). SLC6A8 can also mediate the transport of GAA, however with a $\mathrm{Km}$ value ten times greater than for $\mathrm{Cr}$ (Tachikawa and Hosoya 2011). Therefore, as GAA levels in blood $(1-3.5 \mu \mathrm{M})$ are 2-50 times lower than levels of $\mathrm{Cr}(6-50 \mu \mathrm{M})$, it is unlikely that in physiological conditions GAA is taken up from blood by MCEC (Tachikawa et al. 2009). No elimination of GAA 
from brain parenchyma through BBB could be observed (Tachikawa et al. 2009).

At BCSFB (Fig. 2), in vivo analysis in mouse has also revealed a carrier-mediated uptake of $\mathrm{Cr}$ from blood to CSF through CPEC, with an influx transport clearance of $3.6 \mu \mathrm{L} /$ (min*ml CSF) (Tachikawa et al. 2008). Tachikawa et al. also showed that GAA can be taken up by TR-CSFB cells (immortalized rat choroid plexus cells) and isolated rat choroid plexus used as in vitro model for BCSFB. This uptake of GAA by BCSFB cells appears to be mediated through at least three different mechanisms, two main $\mathrm{Na}^{+} / \mathrm{Cl}^{-}$-dependent carrier activities having the characteristics of SLC6A8 and of the taurine transporter TauT, and a much smaller transmembrane diffusion (Tachikawa et al. 2008). There appears to be a net efflux of GAA through BCSFB, the elimination clearance of CSF to blood through BCSFB (3.97 $\mu \mathrm{L} / \mathrm{min}$ per rat) being about 33 times higher than the blood-to-CSF influx clearance of GAA through BCSFB $(0.12 \mu \mathrm{L} /$ min per rat) (Tachikawa and Hosoya 2011). Efflux of GAA from CSF to blood may thus occur through both SLC6A8 and TauT. However, the much higher concentration of $\mathrm{Cr}(17-90 \mu \mathrm{M})$ than GAA $(0.015-0.114 \mu \mathrm{M})$ in CSF most probably considerably limits the efflux of GAA from CSF through SLC6A8 (Tachikawa et al. 2008).

\section{Cr and GAA at BBB and BCSFB : What can be learned from $\mathrm{Cr}$ deficiency syndromes?}

CNS is the main organ affected in patients suffering from the $\mathrm{Cr}$ deficiency syndromes, inborn errors of $\mathrm{Cr}$ biosynthesis and transport caused by mutations in the GATM, GAMT or SLC6A8 genes (Item et al. 2001; Salomons et al. 2001; Stöckler et al. 1994). Cr-deficient patients present neurological symptoms in infancy (Battini et al. 2002; DeGrauw et al. 2002; Schulze et al. 1997). In particular, intellectual disability and delays in speech acquisition can be observed (AGAT, GAMT and SLC6A8 deficiencies), as well as intractable epilepsy (GAMT and SLC6A8 deficiencies), autism, automutilating behavior, extrapyramidal syndrome and hypotonia (GAMT deficiency) (Stöckler et al. 2007). With the exception of SLC6A8deficient heterozygous females where brain $\mathrm{Cr}$ deficiency is often partial (Cecil et al. 2003; Valayannopoulos et al. 2011; van de Kamp et al. 2011a), the common phenotype of these three primary $\mathrm{Cr}$ deficiencies is the virtual absence of the $\mathrm{Cr}$ peak measured by magnetic resonance spectroscopy (MRS) in cortex and basal ganglia (Stöckler et al. 2007).

AGAT- and GAMT-deficient patients can be treated by oral supplementation of $\mathrm{Cr}$. While this strongly improves their neurological status and CNS development, high doses of $\mathrm{Cr}$ must be used (usually $0.35-2.0 \mathrm{~g} / \mathrm{kg} / \mathrm{day} ; 20-120$ times the normal needs in $\mathrm{Cr}$ ) while replenishment of cerebral $\mathrm{Cr}$ takes months and only results in partial restoration of cerebral Cr pools (Battini et al. 2002; Ganesan et al. 1997; Item et al. 2001; Schulze et al. 1998; Stöckler et al. 1996). One exception to these high doses of $\mathrm{Cr}$ used to treat $\mathrm{Cr}$ deficient patients is a presymptomatic AGAT patient who received $0.1 \mathrm{~g} / \mathrm{kg} /$ day of $\mathrm{Cr}$ since the age of 4 months (Battini et al. 2006). This interesting case is described in more detail in the following chapter on $\mathrm{Cr}$ in immature CNS. A very high dose of creatine $(2.0 \mathrm{~g} / \mathrm{kg} /$ day $)$ was also used in $\mathrm{GAMT}^{/-} \mathrm{KO}$ mice to analyze their CNS replenishment in $\mathrm{Cr}$ (Kan et al. 2007). All these data suggest that BBB has a limited permeability for $\mathrm{Cr}$. Despite improvement of clinical outcome by $\mathrm{Cr}$ supplementation, most AGAT- and GAMTdeficient patients remain with CNS developmental problems. Oral supplementation of $\mathrm{Cr}$ is inefficient in replenishing brain Cr in SLC6A8-deficient patients, who remain with intellectual disability, severe speech impairment and progressive brain atrophy (Bizzi et al. 2002; Cecil et al. 2001; DeGrauw et al. 2002; Póo-Argüelles et al. 2006). This suggests that $\mathrm{Cr}$ cannot enter CNS from periphery by other means than SLC6A8. Attempts to treat SLC6A8-deficient patients with arginine and glycine as precursors of $\mathrm{Cr}$ gave some modest encouraging results in two SLC6A8-deficient patients (Chilosi et al. 2008; Wilcken et al. 2008), while it failed to improve the neurological status of many others (Fons et al. 2008; Valayannopoulos et al. 2011; van de Kamp et al. 2011b). BBB and its surrounding astrocytes efficiently express cationic amino acid transporters (CATs 1 and 2B) allowing the import of arginine from periphery to the blood (Braissant et al. 2001a; Braissant et al. 1999). Altogether, data on the treatment of $\mathrm{Cr}$-deficient patients indicate that $\mathrm{Cr}$ is taken up in limited amounts by CNS from periphery, and that this modest transport of $\mathrm{Cr}$ through $\mathrm{BBB}$ most probably exclusively occurs through SLC6A8 (Béard and Braissant 2010; Braissant and Henry 2008) (Fig. 1).

Despite the almost complete lack of $\mathrm{Cr}$ observed by MRS, Cr remains present within the brain of Cr-deficient patients (Braissant and Henry 2008). In SLC6A8 deficiency, Cr CSF levels do not differ from age-matched controls (Cecil et al. 2001; DeGrauw et al. 2002; Salomons et al. 2001), while total $\mathrm{Cr}$ estimated by MRS has been measured to $1.6 \mathrm{mM}$ in a male patient $(21 \%$ to $35 \%$ of controls; normal range 5.5-7.5 mM; Dezortova et al. 2008). In AGAT deficiency, total $\mathrm{Cr}$ levels in cortical gray matter are decreased to $12 \%$ of age-matched controls (Battini et al. 2002). In GAMT deficiency, CSF Cr levels are strongly decreased $(<2 \mu \mathrm{M}$; normal range: 17-90 $\mu \mathrm{M})$ (Ensenauer et al. 2004; Schulze et al. 1997; Schulze et al. 2003), while in cortical gray matter total $\mathrm{Cr}$ was measured in the 0.2$1.5 \mathrm{mM}$ range (normal range: 5.5-7.5 mM) (Mancini et al. 2005; Stöckler et al. 1994; Dezortova et al. 2008). As the entry of $\mathrm{Cr}$ from periphery to CNS appears to exclusively occur through SLC6A8 at BBB (Tachikawa et al. 2009), the presence of normal levels of $\mathrm{Cr}$ in CSF of SLC6A8-deficient patients and $\mathrm{Cr}$ levels in brain parenchyma between $21 \%$ 
and $29 \%$ of controls must be due to an active CNS endogenous synthesis pathway for $\mathrm{Cr}$ (Dezortova et al. 2008; Béard and Braissant 2010; Braissant et al. 2010). As this endogenous brain $\mathrm{Cr}$ synthesis pathway is invalidated in AGAT and GAMT deficiencies, the low levels of $\mathrm{Cr}$ found in the brain of their respective patients must enter the brain at BBB, through SLC6A8 expressed in MCEC, with the limited efficacy described above (Braissant and Henry 2008; Tachikawa and Hosoya 2011).

GAA accumulation in body fluids is characteristic of GAMT deficiency, where GAA toxicity is responsible for its more complex and specific phenotype. GAA CSF levels in GAMT-deficient patients are $60-1000 \times$ higher than in agematched controls $(6.6-15.3 \mu \mathrm{M}$ versus $0.015-0.114 \mu \mathrm{M})$, while GAA was estimated at $3.6 \mathrm{mM}$ within cortical gray matter (normal range: $1.6 \mathrm{mM}$ ). GAA can also accumulate in the brain of SLC6A8-deficient patients (Sijens et al. 2005). It was shown that both BBB endothelial cells (Tachikawa et al. 2009) and CNS parenchymal cells (Braissant et al. 2010; Tachikawa et al. 2008) are able to take up GAA by SLC6A8. As the Km value of SLC6A8 for GAA (269-412 $\mu \mathrm{M})$ appears ten times higher than that for $\mathrm{Cr}(29-46 \mu \mathrm{M})$ (Tachikawa et al. 2008; Tachikawa and Hosoya 2011), the entry of GAA into CNS in normal conditions must be inhibited by blood $\mathrm{Cr}$ levels (Fig. 1a). Under GAMT deficiency however (Fig. 1b), this entry might be facilitated, blood GAA levels becoming higher than Cr levels (Almeida et al. 2004), therefore contributing to GAA accumulation into the GAMT-deficient brain. Endogenous brain AGAT activity must also contribute to GAA accumulation in the CNS of GAMT-deficient patients (Braissant and Henry 2008). Similarly, GAA accumulating in the brain of some SLC6A8-deficient patients (Sijens et al. 2005) is most probably essentially due to brain AGAT activity and the impossibility for GAA to enter GAMT-expressing cells as functional SLC6A8 is lacking (Béard and Braissant 2010; Braissant et al. 2010), and to the lack of SLC6A8mediated GAA efflux at BCSFB (Tachikawa and Hosoya 2011). Normal levels of GAA in the plasma of SLC6A8deficient patients most probably makes negligible the contribution of GAA passive diffusion at BBB (Tachikawa et al. 2009) for CNS GAA accumulation in SLC6A8-deficiency. SLC6A8 as well as TauT expressed in the brush-border membrane of choroid plexus at BCSFB may contribute, in GAMT and maybe SLC6A8 deficiencies, to some elimination of GAA from CSF (Tachikawa et al. 2008; Tachikawa et al. 2009; Tachikawa and Hosoya 2011) (Fig. 2b).

\section{Models of transport of $\mathrm{Cr}$ and GAA at BBB and BCSFB}

Taken together, experimental data on (i) SLC6A8 expression, (ii) functional analysis of $\mathrm{Cr}$ and GAA transport and (iii) activity and characterization of SLC6A8 and TauT at
$\mathrm{BBB}$ and BCSFB, as well as (iv) the brain characteristics of $\mathrm{Cr}$-deficient patients and the way they respond to $\mathrm{Cr}$ treatment, suggest the following models for $\mathrm{Cr}$ and GAA transport through BBB and BCSFB (Figs. 1 and 2).

At BBB, SLC6A8 is expressed on both luminal and abluminal sides of MCEC (Fig. 1). In physiological conditions (Fig. 1a), a net entry of $\mathrm{Cr}$ from periphery to CNS occurs, most probably through SLC6A8 only. This uptake of peripheral $\mathrm{Cr}$ by the brain is limited, due to the absence of SLC6A8 in the astrocytic feet covering most of BBB and the weak diffusion of $\mathrm{Cr}$ through the surrounding ECM. CNS can ensure its own $\mathrm{Cr}$ synthesis thanks to endogenous expression of AGAT and GAMT, which appear dissociated in most regions of the brain, thus necessitating the transfer of GAA from AGAT- to GAMT-expressing cells through SLC6A8 for completing Cr synthetic pathway. No transfer of GAA occurs through BBB in normal conditions, due to the favorable competition of $\mathrm{Cr}$ over GAA for SLC6A8. Under GAMT deficiency however, the competition for SLC6A8 is reversed in favor of GAA, which may cross $\mathrm{BBB}$ from periphery and contributes, together with the endogenous brain AGAT activity, to GAA accumulation in the brain of GAMT-deficient patients (Fig. 1b). So far, nothing is known on the use of $\mathrm{Cr}$ by pericytes. Equally, the role of SLC6A8 on the abluminal side of MCEC, as well as the way $\mathrm{Cr}$ and GAA can leave the cells, are not understood (Fig. 1a).

At BCSFB, SLC6A8 is predominantly expressed on the brush-border apical side of CPEC, as well as weaker on their basal side (Fig. 2). In physiological conditions (Fig. 2a), it is not clear whether a net entry of $\mathrm{Cr}$ from periphery, or exit of $\mathrm{Cr}$ from CSF, occur at BCSFB. There appears to be a net exit of GAA from CSF to blood, predominantly through TauT. This net exit of GAA from CSF to blood through BCSFB may be stronger under GAMT deficiency (Fig. 2b), and may occur both through TauT and SLC6A8 (favorable competition of GAA over $\mathrm{Cr}$ ). The exchanges of $\mathrm{Cr}$ and GAA between CSF and brain parenchyma, and particularly its extracellular fluid, are not clearly understood so far.

\section{Brain Cr : Different roles for BCSFB and BBB between immature and mature CNS}

As proposed above, adult (or mature) CNS might privilege $\mathrm{Cr}$ endogenous synthesis versus uptake from periphery. The fetal and perinatal (or immature) brain probably behaves differently. In mammals, the fetal needs in $\mathrm{Cr}$ are partly supported by transport of $\mathrm{Cr}$ from mother to fetus (Davis et al. 1978; Ireland et al. 2008; Ireland et al. 2011). On the other side, AGAT, GAMT and SLC6A8 are well expressed during embryogenesis, including in CNS (Braissant et al. 2005; Ireland et al. 2009; Wang et al. 2007). However, the 
low level of GAMT in early stages suggests that, in contrast to adult brain, fetal and perinatal CNS may predominantly depend on Cr supply from periphery (Braissant et al. 2007). BCSFB develops much earlier than BBB, and is thus the first structure responsible for exchanges between periphery and CNS during development (Fig. 3). The Cr supply to CNS from periphery is probably made possible by the much higher expression of SLC6A8 in CPEC (BCSFB) during development (Braissant et al. 2005) than in the mature brain (Braissant et al. 2001b; Tachikawa et al. 2008), as well as by the very high expression of SLC6A8 in fetal ependymal cells and periventricular zone, as shown in rat (Braissant et al. 2005) and human embryos (O.Braissant and H.R. Widmer, unpublished results) (Fig. 3). In contrast at BBB, SLC6A8 is not detectable in the first stages of MCEC development (Braissant et al. 2005), while it is expressed in mature MCEC (Braissant et al. 2001b; Ohtsuki et al. 2002) (Fig. 3).

The better capacity of immature CNS to take up Cr from periphery is illustrated in two recent studies that showed that the pre-symptomatic treatment of AGAT and GAMT deficiencies appears to completely prevent the phenotypic expression of these diseases (Schulze and Battini 2007). An AGAT-deficient boy, brother of two already affected AGATdeficient sisters, was diagnosed at birth with the same homozygous mutation as his sisters, and treated orally since the age of 4 months with $\mathrm{Cr}$ monohydrate $(0.1 \mathrm{~g} / \mathrm{kg} / \mathrm{day}$; Battini et al. 2006). Similarly, a GAMT-deficient girl, sister of an already affected GAMT-deficient brother, was diagnosed at birth with the same mutations as her brother, and treated orally since the age of 22 days with $\mathrm{Cr}$ monohydrate $(0.4 \mathrm{~g} / \mathrm{kg} /$ day; Schulze et al. 2006). Both patients, over a follow-up of more than 5 years, did not develop the characteristic CNS phenotypic expression of AGAT and GAMT deficiencies (Schulze and Battini 2007). These two cases suggest that Cr plays an essential role in the development of CNS higher cognitive functions, like speech acquisition, during the first months and years of life, and that treatment with $\mathrm{Cr}$ before irreversible damage occurs may prevent clinical symptoms of AGAT and GAMT deficiencies permanently. As described above, the pre-symptomatic treatment with $\mathrm{Cr}$ in post-natal stages and during the first years of life may also facilitate the entry of $\mathrm{Cr}$ into the brain, at stages where $\mathrm{BBB}$ is not as tightly regulated as in more mature stages, and where SLC6A8 expression on BBB and BCSFB may still largely facilitate entry of peripheral $\mathrm{Cr}$ into the brain (Braissant et al. 2005; Ireland et al. 2009), in contrast to adulthood (Braissant et al. 2001b) (Fig. 3). This facilitated entry of Cr into CNS during the first months and years of life may explain the success of the lower dose of $\mathrm{Cr}$ used $(0.1 \mathrm{~g} / \mathrm{kg} /$ day $)$ to treat the above-described pre-symptomatic AGAT-deficient patient (Battini et al. 2006).

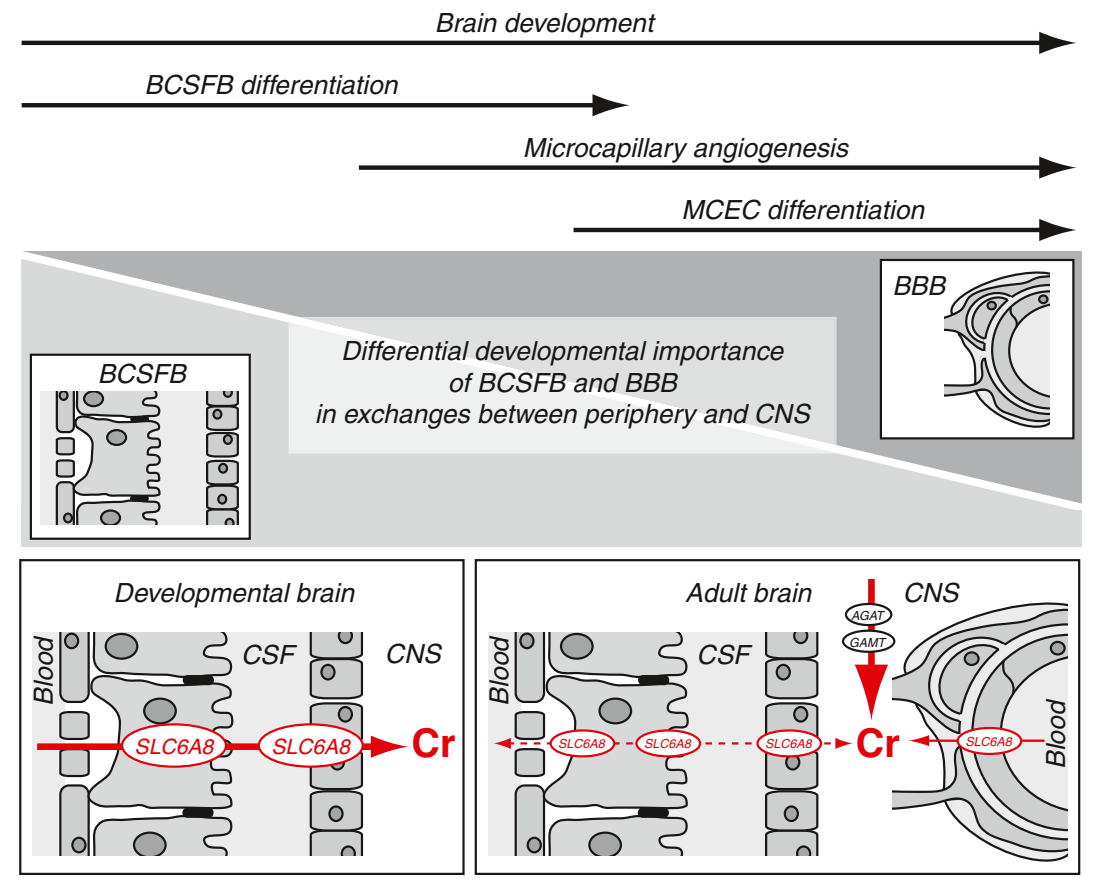

Fig. 3 Transport of creatine $(\mathrm{Cr})$ at blood-cerebrospinal fluid barrier (BCSFB) and blood-brain barrier (BBB) in the developmental versus the adult brain. Fetal and perinatal CNS may predominantly depend on $\mathrm{Cr}$ supply from periphery. This is probably made possible during development by the high expression of SLC6A8 in CPEC at BCSFB as well as in fetal ependymal cells and periventricular zone. In contrast,
$\mathrm{Cr}$ is supplied to the mature brain by its limited uptake from periphery, predominantly at BBB, as well as by endogenous synthesis. AGAT: arginine:glycine amidinotransferase; CNS: central nervous system; $\mathrm{Cr}$ : creatine; CSF: cerebrospinal fluid; GAMT: guanidinoacetate methyltransferase; MCEC: microcapillary endothelial cells (BBB); SLC6A8: Cr transporter 


\section{Change of BBB properties for $\mathrm{Cr}$ in brain pathology?}

Numerous pathological states of the brain lead to changes or disturbances of BBB, that can range from adaptation of transporter expression and activity to a frank rupture of BBB (Engelhardt and Sorokin 2009; Neuwelt et al. 2011). This is also true for astrocytes, which are known to become reactive in many CNS pathological conditions (Zhang and Barres 2010). In recent years, we have shown that hyperammonemic conditions lead to a secondary $\mathrm{Cr}$ deficiency in brain cells (Bachmann et al. 2004; Braissant et al. 2008; Braissant 2010b), and that $\mathrm{Cr}$ co-treatment exerts neuroprotective effects against $\mathrm{NH}_{4}^{+}$toxicity (Braissant et al. 2002; Braissant 2010a; Cagnon and Braissant 2007). While SLC6A8 appears absent from astrocytes in normal, physiological conditions, we could show interestingly that $\mathrm{NH}_{4}{ }^{+}$ exposure induces SLC6A8 expression in these same astrocytes (Braissant et al. 2008). Moreover, $\mathrm{NH}_{4}{ }^{+}$exposure also increases both SLC6A8 expression and $\mathrm{Cr}$ uptake in MCEC (Bélanger et al. 2007). Thus, BBB in the hyperammonemic CNS might be more permeable to $\mathrm{Cr}$ than under physiological conditions, and supplying oral $\mathrm{Cr}$ to hyperammonemic neonates or infants might likely contribute to protect their brain development (Braissant 2010a; Braissant 2010b). This has to be put in perspective of the treatment of other brain pathologies with $\mathrm{Cr}$. Indeed, $\mathrm{Cr}$ administration can exert protective effects in various neurodegenerative processes, including Huntington's and Parkinson's diseases (Béard and Braissant 2010; Bender et al. 2006; Hersch et al. 2006; Klein and Ferrante 2007). Creatine was also demonstrated to exert neuroprotective effects, both in vitro and in vivo, against anoxic and ischemic damage (Balestrino et al. 2002; Adcock et al. 2002; Lensman et al. 2006) as well as against traumatic brain injury (Sullivan et al. 2000) and spinal cord injury (Hausmann et al. 2002).

\section{Creatine derivatives for a better crossing of BBB?}

To counteract the limited permeability of BBB for $\mathrm{Cr}$, and in particular to allow a treatment for SLC6A8-deficient patients, a lot of work has been performed in order to develop more lipophilic derivatives of $\mathrm{Cr}$, that would not need SLC6A8 to be taken up by cells, and that in consequence would cross BBB more easily, possibly by simple trans-membrane diffusion. While some derivatives (e.g., Namidino-piperidine) were harmful, others (e.g., Cr-Mgcomplex acetate, $\mathrm{PCr}-\mathrm{Mg}$-complex acetate and $\mathrm{Cr}$ ethyl ester) showed interesting neuroprotective effects in hippocampal organotypic cultures (a model with disruption of BBB) (Perasso et al. 2008; Adriano et al. 2011). PCr-Mgcomplex acetate and another derivative, Cr benzyl ester, were also demonstrated to cross cell membranes without the help of the $\mathrm{Cr}$ transporter (Lunardi et al. 2006). More interestingly, $\mathrm{PCr}-\mathrm{Mg}$-complex acetate and the very recently described creatinyl amino acids showed neuroprotective effects in vivo in rodents, thus suggesting a crossing of BBB (Burov et al. 2011; Perasso et al. 2009). However so far, only the $\mathrm{Cr}$ derivative $\mathrm{Cr}$ ethyl ester has been used to treat SLC6A8-deficient patients (Fons et al. 2010), but this compound failed to replenish their brain $\mathrm{Cr}$ concentration, as well as to improve their neurological status. This is probably due to the non-enzymatic conversion of Cr ethyl ester directly to creatinine, before it reaches CNS (Giese and Lecher 2009). For the treatment of SLC6A8deficient patients, no data are available so far for the use of other $\mathrm{Cr}$ derivatives, in particular those that seem to cross BBB (PCr-Mg-complex acetate and creatinyl amino acids).

\section{Models and conclusions}

Taken together, (i) the expression patterns of SLC6A8, AGAT and GAMT at BBB, BCSFB and in the brain, (ii) the functional experiments on $\mathrm{Cr}$ and GAA trafficking through $\mathrm{BBB}$ and BCSFB both in vivo and in in vitro models, and (iii) the clinical characteristics of Cr-deficient patients, lead to the following models for $\mathrm{Cr}$ and GAA transport between periphery and CNS, and for Cr synthesis in CNS (Figs. 1, 2 and 3) (Béard and Braissant 2010; Braissant et al. 2011; Braissant and Henry 2008):

In normal conditions, $\mathrm{Cr}$ is taken up by $\mathrm{CNS}$ from periphery through SLC6A8 expressed on MCEC at BBB, but in limited amounts because of the absence of SLC6A8 in the surrounding astrocytes and the difficult diffusion of $\mathrm{Cr}$ through ECM surrounding BBB. In consequence, the brain needs its own synthesis to ensure sufficient levels of $\mathrm{Cr}$, and does so by expressing AGAT and GAMT. No uptake of GAA from periphery occurs at BBB, except under GAMT deficiency (and maybe also SLC6A8 deficiency). A net exit of GAA seems to occur from CSF to blood at BCSFB under physiological conditions, predominantly through TauT. This exit of GAA from CSF to blood may be increased under GAMT deficiency, and uses both TauT and SLC6A8.

A lot of work is still needed to better understand the transport of $\mathrm{Cr}$, GAA and potentially active $\mathrm{Cr}$ derivatives at BBB and BCSFB, and to allow better treatment for Cr-deficient patients, in particular those with SLC6A8 deficiency. In particular, a better knowledge of how $\mathrm{Cr}$ and GAA can leave the cells, which so far is very poorly understood (Figs. 1 and 2), may contribute to more focused and rationale treatments.

Acknowledgments Our work is supported by the Swiss National Science Foundation, grants 3100A0-116859 and 31003A-130278. 


\section{References}

Acosta ML, Kalloniatis M, Christie DL (2005) Creatine transporter localization in developing and adult retina: importance of creatine to retinal function. Am J Physiol Cell Physiol 289:C1015-C1023

Adcock KH, Nedelcu J, Loenneker T, Martin E, Wallimann T, Wagner BP (2002) Neuroprotection of creatine supplementation in neonatal rats with transient cerebral hypoxia-ischemia. Dev Neurosci $24: 382-388$

Adriano E, Garbati P, Damonte G, Salis A, Armirotti A, Balestrino M (in press) Searching for a therapy of creatine transporter deficiency: Some effects of creatine ethyl ester in brain slices in vitro. Neuroscience

Almeida LS, Verhoeven NM, Roos B et al. (2004) Creatine and guanidinoacetate: diagnostic markers for inborn errors in creatine biosynthesis and transport. Mol Genet Metab 82:214-219

Almeida LS, Salomons GS, Hogenboom F, Jakobs C, Schoffelmeer AN (2006) Exocytotic release of creatine in rat brain. Synapse $60: 118-123$

Bachmann C, Braissant O, Villard AM, Boulat O, Henry H (2004) Ammonia toxicity to the brain and creatine. Mol Genet Metab 81 (Suppl 1):S52-S57

Balestrino M, Lensman M, Parodi M, Perasso L, Rebaudo R, Melani R, Polenov S, Cupello A (2002) Role of creatine and phosphocreatine in neuronal protection from anoxic and ischemic damage. Amino Acids 23:221-229

Battini R, Leuzzi V, Carducci C et al. (2002) Creatine depletion in a new case with AGAT deficiency: clinical and genetic study in a large pedigree. Mol Genet Metab 77:326-331

Battini R, Alessandri MG, Leuzzi V et al. (2006) Arginine:glycine amidinotransferase (AGAT) deficiency in a newborn: early treatment can prevent phenotypic expression of the disease. J Pediatr 148:828-830

Béard E, Braissant O (2010) Synthesis and transport of creatine in the CNS: importance for cerebral functions. J Neurochem 115:297-313

Bélanger M, Asashima T, Ohtsuki S, Yamaguchi H, Ito S, Terasaki T (2007) Hyperammonemia induces transport of taurine and creatine and suppresses claudin-12 gene expression in brain capillary endothelial cells in vitro. Neurochem Int 50:95-101

Bender A, Koch W, Elstner M et al. (2006) Creatine supplementation in Parkinson disease: a placebo-controlled randomized pilot trial. Neurology 67:1262-1264

Bizzi A, Bugiani M, Salomons GS et al. (2002) X-linked creatine deficiency syndrome: a novel mutation in creatine transporter gene SLC6A8. Ann Neurol 52:227-231

Bothwell JH, Styles P, Bhakoo KK (2002) Swelling-activated taurine and creatine effluxes from rat cortical astrocytes are pharmacologically distinct. J Membr Biol 185:157-164

Braissant O (2010a) Ammonia toxicity to the brain: effects on creatine metabolism and transport and protective roles of creatine. Mol Genet Metab 100(Suppl 1):S53-S58

Braissant O (2010b) Current concepts in the pathogenesis of urea cycle disorders. Mol Gen Metab 100(Suppl 1):S3-S12

Braissant O, Henry H (2008) AGAT, GAMT and SLC6A8 distribution in the central nervous system, in relation to creatine deficiency syndromes: a review. J Inher Metab Dis 31:230-239

Braissant O, Gotoh T, Loup M, Mori M, Bachmann C (1999) Larginine uptake, the citrulline-NO cycle and arginase II in the rat brain: an in situ hybridization study. Mol Brain Res 70:231-241

Braissant O, Gotoh T, Loup M, Mori M, Bachmann C (2001a) Differential expression of the cationic amino acid transporter 2(B) in the adult rat brain. Mol Brain Res 91:189-195

Braissant O, Henry H, Loup M, Eilers B, Bachmann C (2001b) Endogenous synthesis and transport of creatine in the rat brain: an in situ hybridization study. Mol Brain Res 86:193-201
Braissant O, Henry H, Villard AM et al. (2002) Ammonium-induced impairment of axonal growth is prevented through glial creatine. J Neurosci 22:9810-9820

Braissant O, Henry H, Villard AM, Speer O, Wallimann T, Bachmann $\mathrm{C}$ (2005) Creatine synthesis and transport during rat embryogenesis: spatiotemporal expression of AGAT, GAMT and CT1. BMC Dev Biol 5:9

Braissant O, Bachmann C, Henry H (2007) Expression and function of AGAT, GAMT and CT1 in the mammalian brain. Subcell Biochem 46:67-81

Braissant O, Cagnon L, Monnet-Tschudi F et al. (2008) Ammonium alters creatine transport and synthesis in a 3D-culture of developing brain cells, resulting in secondary cerebral creatine deficiency. Eur J Neurosci 27:1673-1685

Braissant O, Béard E, Torrent C, Henry H (2010) Dissociation of AGAT, GAMT and SLC6A8 in CNS: relevance to creatine deficiency syndromes. Neurobiol Dis 37:423-433

Braissant O, Henry H, Beard E, Uldry J (2011) Creatine deficiency syndromes and the importance of creatine synthesis in the brain. Amino Acids 40:1315-1324

Brosnan JT, Brosnan ME (2007) Creatine: endogenous metabolite, dietary, and therapeutic supplement. Annu Rev Nutr 27:241-261

Burov S, Leko M, Dorosh M, Dobrodumov A, Veselkina O (2011) Creatinyl amino acids-new hybrid compounds with neuroprotective activity. J Pept Sci 17:620-626

Cagnon L, Braissant O (2007) Hyperammonemia-induced toxicity for the developing central nervous system. Brain Res Rev 56:183197

Cardoso FL, Brites D, Brito MA (2010) Looking at the blood-brain barrier: molecular anatomy and possible investigation approaches. Brain Res Rev 64:328-363

Cecil KM, Salomons GS, Ball WS et al. (2001) Irreversible brain creatine deficiency with elevated serum and urine creatine: a creatine transporter defect? Ann Neurol 49:401-404

Cecil KM, DeGrauw TJ, Salomons GS, Jakobs C, Egelhoff JC, Clark JF (2003) Magnetic resonance spectroscopy in a 9-day-old heterozygous female child with creatine transporter deficiency. J Comput Assist Tomogr 27:44-47

Chanutin A (1927) A study on the effect of creatine on growth and its distribution in the tissues of normal rats. J Biol Chem 75:549-557

Chilosi A, Leuzzi V, Battini R et al. (2008) Treatment with L-arginine improves neuropsychological disorders in a child with creatine transporter defect. Neurocase 14:151-161

Davis BM, Miller RK, Brent RL, Koszalka TR (1978) Materno-fetal transport of creatine in the rat. Biol Neonate 33:43-54

Dechent P, Pouwels PJ, Wilken B, Hanefeld F, Frahm J (1999) Increase of total creatine in human brain after oral supplementation of creatine-monohydrate. Am J Physiol 277:R698R704

DeGrauw TJ, Salomons GS, Cecil KM et al. (2002) Congenital creatine transporter deficiency. Neuropediatrics 33:232-238

Dezortova M, Jiru F, Petrasek J, Malinova V, Zeman J, Jirsa M, Hajek $\mathrm{M}(2008){ }^{1} \mathrm{H}$ MR spectroscopy as a diagnostic tool for cerebral creatine deficiency. Magn Reson Mater Phy 21:327-332

Dityatev A, Seidenbecher CI, Schachner M (2010) Compartmentalization from the outside: the extracellular matrix and functional microdomains in the brain. Trends Neurosci 33:503-512

Engelhardt B, Sorokin L (2009) The blood-brain and the bloodcerebrospinal fluid barriers: function and dysfunction. Semin Immunopathol 31:497-511

Ensenauer R, Thiel T, Schwab KO et al. (2004) Guanidinoacetate methyltransferase deficiency: differences of creatine uptake in human brain and muscle. Mol Genet Metab 82:208-213

Fons C, Sempere A, Arias A et al. (2008) Arginine supplementation in four patients with X-linked creatine transporter defect. J Inherit Metab Dis 31:724-728 
Fons C, Arias A, Sempere A et al. (2010) Response to creatine analogs in fibroblasts and patients with creatine transporter deficiency. Mol Genet Metab 99:296-299

Ganesan V, Johnson A, Connelly A, Eckhardt S, Surtees RA (1997) Guanidinoacetate methyltransferase deficiency: new clinical features. Pediatr Neurol 17:155-157

Giese MW, Lecher CS (2009) Non-enzymatic cyclization of creatine ethyl ester to creatinine. Biochem Biophys Res Commun 388:252-255

Happe HK, Murrin LC (1995) In situ hybridization analysis of CHOT1, a creatine transporter, in the rat central nervous system. J Comp Neurol 351:94-103

Hasselbalch SG, Knudsen GM, Jakobsen J, Hageman LP, Holm S, Paulson OB (1995) Blood-brain barrier permeability of glucose and ketone bodies during short-term starvation in humans. Am J Physiol 268:E1161-E1166

Hausmann ON, Fouad K, Wallimann T, Schwab ME (2002) Protective effects of oral creatine supplementation on spinal cord injury in rats. Spinal Cord 40:449-456

Hersch SM, Gevorkian S, Marder K et al. (2006) Creatine in Huntington disease is safe, tolerable, bioavailable in brain and reduces serum 8OH2'dG. Neurology 66:250-252

Ireland Z, Dickinson H, Snow R, Walker DW (2008) Maternal creatine: does it reach the fetus and improve survival after an acute hypoxic episode in the spiny mouse (Acomys cahirinus)? Am J Obstet Gynecol 198:431-436

Ireland Z, Russell AP, Wallimann T, Walker DW, Snow R (2009) Developmental changes in the expression of creatine synthesizing enzymes and creatine transporter in a precocial rodent, the spiny mouse. BMC Dev Biol 9:39

Ireland Z, Castillo-Melendez M, Dickinson H, Snow R, Walker DW (2011) A maternal diet supplemented with creatine from midpregnancy protects the newborn spiny mouse brain from birth hypoxia. Neuroscience

Item CB, Stöckler-Ipsiroglu S, Stromberger C et al. (2001) Arginine: glycine amidinotransferase deficiency: the third inborn error of creatine metabolism in humans. Am J Hum Genet 69:1127-1133

Kan HE, Meeuwissen E, van Asten JJ, Veltien A, Isbrandt D, Heerschap A (2007) Creatine uptake in brain and skeletal muscle of mice lacking guanidinoacetate methyltransferase assessed by magnetic resonance spectroscopy. J Appl Physiol 102:2121-2127

Klein AM, Ferrante RJ (2007) The neuroprotective role of creatine. Subcell Biochem 46:205-243

Lensman M, Korzhevskii DE, Mourovets VO, Kostkin VB, Izvarina N, Perasso L, Gandolfo C, Otellin VA, Polenov SA, Balestrino M (2006) Intracerebroventricular administration of creatine protects against damage by global cerebral ischemia in rat. Brain Res 1114:187-194

Lunardi G, Parodi A, Perasso L et al. (2006) The creatine transporter mediates the uptake of creatine by brain tissue, but not the uptake of two creatine-derived compounds. Neuroscience 142:991-997

Mak CS, Waldvogel HJ, Dodd JR et al. (2009) Immunohistochemical localisation of the creatine transporter in the rat brain. Neuroscience 163:571-585

Mancini GM, Catsman-Berrevoets CE et al. (2005) Two novel mutations in SLC6A8 cause creatine transporter defect and distinctive $\mathrm{X}$-linked mental retardation in two unrelated Dutch families. Am J Med Genet A 132:288-295

Nakashima T, Tomi M, Katayama K et al. (2004) Blood-to-retina transport of creatine via creatine transporter (CRT) at the rat inner blood-retinal barrier. J Neurochem 89:1454-1461

Nakashima T, Tomi M, Tachikawa M, Watanabe M, Terasaki T, Hosoya K (2005) Evidence for creatine biosynthesis in Müller glia. GLIA 52:47-52

Neuwelt EA, Bauer B, Fahlke C et al. (2011) Engaging neuroscience to advance translational research in brain barrier biology. Nat Rev Neurosci 12:169-182
Ohtsuki S, Tachikawa M, Takanaga H et al. (2002) The bloodbrain barrier creatine transporter is a major pathway for supplying creatine to the brain. J Cereb Blood Flow Metab 22:1327-1335

Perasso L, Cupello A, Lunardi GL, Principato C, Gandolfo C, Balestrino M (2003) Kinetics of creatine in blood and brain after intraperitoneal injection in the rat. Brain Res 974:37-42

Perasso L, Lunardi GL, Risso F et al. (2008) Protective effects of some creatine derivatives in brain tissue anoxia. Neurochem Res 33:765-775

Perasso L, Adriano E, Ruggeri P, Burov SV, Gandolfo C, Balestrino M (2009) In vivo neuroprotection by a creatine-derived compound: phosphocreatine-Mg-complex acetate. Brain Res 1285:158-163

Pisano JJ, Abraham D, Udenfriend S (1963) Biosynthesis and disposition of g-guanidinobutyric acid in mammalian tissues. Arch Biochem Biophys 100:323-329

Póo-Argüelles P, Arias A, Vilaseca MA et al. (2006) X-Linked creatine transporter deficiency in two patients with severe mental retardation and autism. J Inherit Metab Dis 29:220-223

Salomons GS, van Dooren SJ, Verhoeven NM et al. (2001) X-linked creatine-transporter gene (SLC6A8) defect: a new creatinedeficiency syndrome. Am J Hum Genet 68:1497-1500

Schloss P, Mayser W, Betz H (1994) The putative rat choline transporter CHOT1 transports creatine and is highly expressed in neural and muscle-rich tissues. Biochem Biophys Res Commun 198:637-645

Schmidt A, Marescau B, Boehm EA et al. (2004) Severely altered guanidino compound levels, disturbed body weight homeostasis and impaired fertility in a mouse model of guanidinoacetate $\mathrm{N}$ methyltransferase (GAMT) deficiency. Hum Mol Genet 13:905921

Schulze A (2005) Strategies in the treatment of GAMT deficiency. In Jakobs C, Stöckler-Ipsiroglu S, eds; Verhoeven NM, Salomons GS, co-eds. Clinical and molecular aspects of defects in creatine and polyol metabolism. Heilbronn: SPS Verlagsgesellschaft, 1933

Schulze A, Battini R (2007) Pre-symptomatic treatment of creatine biosynthesis defects. Subcell Biochem 46:167-181

Schulze A, Hess T, Wevers R et al. (1997) Creatine deficiency syndrome caused by guanidinoacetate methyltransferase deficiency: diagnostic tools for a new inborn error of metabolism. J Pediatr 131:626-631

Schulze A, Mayatepek E, Bachert P, Marescau B, De Deyn PP, Rating $\mathrm{D}$ (1998) Therapeutic trial of arginine restriction in creatine deficiency syndrome. Eur J Pediatr 157:606-607

Schulze A, Bachert P, Schlemmer H et al. (2003) Lack of creatine in muscle and brain in an adult with GAMT deficiency. Ann Neurol $53: 248-251$

Schulze A, Hoffmann GF, Bachert P et al. (2006) Presymptomatic treatment of neonatal guanidinoacetate methyltransferase deficiency. Neurology 67:719-721

Sijens PE, Verbruggen KT, Oudkerk M, van Spronsen FJ, SooraniLunsing RJ (2005) ${ }^{1} \mathrm{H}$ MR spectroscopy of the brain in $\mathrm{Cr}$ transporter defect. Mol Genet Metab 86:421-422

Spector R (2010) Nature and consequences of mammalian brain and CSF efflux transporters: four decades of progress. J Neurochem 112:13-23

Stöckler S, Holzbach U, Hanefeld F et al. (1994) Creatine deficiency in the brain: a new, treatable inborn error of metabolism. Pediatr Res 36:409-413

Stöckler S, Hanefeld F, Frahm J (1996) Creatine replacement therapy in guanidinoacetate methyltransferase deficiency, a novel inborn error of metabolism. Lancet 348:789-790

Stöckler S, Schutz PW, Salomons GS (2007) Cerebral creatine deficiency syndromes: Clinical aspects, treatment and pathophysiology. Subcell Biochem 46:149-166 
Sullivan PG, Geiger JD, Mattson MP, Scheff SW (2000) Dietary supplement creatine protects against traumatic brain injury. Ann Neurol 48:723-729

Tachikawa M, Hosoya K (2011) Transport characteristics of guanidino compounds at the blood-brain barrier and blood-cerebrospinal fluid barrier: relevance to neural disorders. Fluids Barriers CNS 8:13

Tachikawa M, Fukaya M, Terasaki T, Ohtsuki S, Watanabe M (2004) Distinct cellular expressions of creatine synthetic enzyme GAMT and creatine kinases uCK-Mi and CK-B suggest a novel neuronglial relationship for brain energy homeostasis. Eur J Neurosci 20:144-160

Tachikawa M, Fujinawa J, Takahashi M et al. (2008) Expression and possible role of creatine transporter in the brain and at the bloodcerebrospinal fluid barrier as a transporting protein of guanidinoacetate, an endogenous convulsant. J Neurochem 107:768-778

Tachikawa M, Kasai Y, Yokoyama R et al. (2009) The blood-brain barrier transport and cerebral distribution of guanidinoacetate in rats: involvement of creatine and taurine transporters. J Neurochem

Valayannopoulos V, Boddaert N, Chabli A et al. (2011) Treatment by oral creatine, L-arginine and L-glycine in six severely affected patients with creatine transporter defect. J Inherit Metab Dis van de Kamp JM, Pouwels PJ, Aarsen FK et al. (2011a) Longterm follow-up and treatment in nine boys with X-linked creatine transporter defect. J Inherit Metab Dis Epub ahead of print

van de Kamp JM, Mancini GMS, Pouwels PJW, Betsalel OT, van Dooren SJM, de Koning I, Steenweg ME, Jakobs C, van der Knaap MS, Salomons GS (2011b) Clinical features and Xinactivation in females heterozygous for creatine transporter defect. Clin Genet 79:199-299

Wang L, Zhang Y, Shao M, Zhang H (2007) Spatiotemporal expression of the creatine metabolism related genes agat, gamt and ct1 during zebrafish embryogenesis. Int J Dev Biol 51:247-253

Wilcken B, Fagan E, Sim K, Carpenter KH, Salomons GS (2008) Creatine transporter defect: results of 6 months' treatment. J Inher Metab Dis 31(Suppl):70

Wolburg H, Paulus W (2010) Choroid plexus: biology and pathology. Acta Neuropathol 119:75-88

Wyss M, Kaddurah-Daouk R (2000) Creatine and creatinine metabolism. Physiol Rev 80:1107-1213

Zhang Y, Barres BA (2010) Astrocyte heterogeneity: an underappreciated topic in neurobiology. Curr Opin Neurobiol 20:588-594 